\title{
French Society of Digestive Endoscopy SFED guideline: monitoring of patients with Barrett's esophagus
}

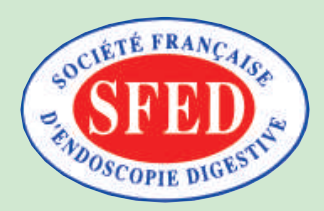

Authors

J. Boyer, R. Laugier, M. Chemali, J. P. Arpurt, C. Boustière, J. M. Canard, P. A. Dalbies, G. Gay, J. Escourrou, B. Napoléon, L. Palazzo, T. Ponchon, B. Richard-Mollard, D. Sautereau, G. Tucat, B. Vedrenne

Bibliography

DOI $10.1055 / \mathrm{s}-2007-966653$

Endoscopy 2007; 39:

840-842 @ Georg Thieme

Verlag KG Stuttgart · New York ISSN 0013-726X

\section{Corresponding author}

T. Ponchon

SFED, 96 boulevard du Montparnasse, 75014 Paris

Fax: +33140540066

secretariat@sfed.org

\section{Definitions \\ $\nabla$}

Diagnosis of Barrett's esophagus, also known as Barrett's mucosa, is by two means, endoscopic and histologic. Endoscopically, the condition is defined as a columnar epithelium that extends above the gastroesophageal junction (GEJ); histologically, it is defined by the presence of a specialized intestinal metaplasia.

Barrett's esophagus is classified into three types according to its length:

- Long-segment Barrett's esophagus: when the distance between the GEJ and the squamocolumnar epithelial line (Z-line) is more than $3 \mathrm{~cm}$ long.

- Short-segment Barrett's esophagus: when the distance between the GEJ and the Z-line is from $5 \mathrm{~mm}$ to $3 \mathrm{~cm}$ long. It may be circular like a sleeve or segmented into tongue(s).

- Ultra-short-segment Barrett's esophagus: when the distance between the GEJ and the Zline is less than $5 \mathrm{~mm}$ long. This entity cannot be diagnosed endoscopically since it cannot be distinguished from the cardial intestinal metaplasia.

\section{When to monitor}

$\nabla$

- Patient has long- or short-segment Barrett's esophagus.

- Patient age and general status are compatible with treatment should malignancy occur. In elderly patients with a life expectancy of several years, monitoring should be proposed only when the first biopsies show dysplasia.

\section{Endoscopic technique}

$\nabla$

The GEJ must be carefully examined in every patient undergoing gastroscopy for whatever indication and even in the absence of symptoms of gastroesophageal reflux disease (GERD). This examination must be performed while the endoscope is on the way down. Using insufflation, all the time needed must be taken in order to examine the cardia in its closed and open positions. The endoscope must be positioned a few centimeters above the GEJ, which is located at the most proximal extent of the gastric folds or at the distal extent of the palisade vessels. The Zline must also be examined along its entire length.

In cases of severe esophagitis, treatment with proton pump inhibitors (PPIs) must be started and follow-up endoscopy performed 6-8 weeks later. If possible during the first endoscopy, the biopsies should be taken according to the protocol described in $\odot$ Table 1. Otherwise, especially

\begin{tabular}{|c|c|}
\hline No dysplasia & $\begin{array}{l}\text { Short-segment } \mathrm{BE}(<3 \mathrm{~cm}) \text { : } \\
\text { endoscopy + biopsies every } 5 \text { years } \\
\text { Long-segment } \mathrm{BE}(3-6 \mathrm{~cm}) \text { : } \\
\text { endoscopy + biopsies every } 3 \text { years } \\
\text { Long-segment } \mathrm{BE}(>6 \mathrm{~cm}) \text { : } \\
\text { endoscopy + biopsies every } 2 \text { years }\end{array}$ \\
\hline $\begin{array}{l}\text { Low-grade } \\
\text { dysplasia }\end{array}$ & $\begin{array}{l}\text { Double-dose PPI treatment for } \\
2 \text { months } \\
\text { Prior repeated endoscopy + biopsies } \\
\text { If low grade confirmed, endoscopy + } \\
\text { biopsies at } 6 \text { months, } 1 \text { year, then } \\
\text { yearly }\end{array}$ \\
\hline $\begin{array}{l}\text { High-grade } \\
\text { dysplasia }\end{array}$ & $\begin{array}{l}\text { Double-dose PPI treatment for } \\
1-2 \text { months } \\
\text { Prior repeated endoscopy + biopsies } \\
\text { If high grade confirmed, endoscopic } \\
\text { or surgical treatment }\end{array}$ \\
\hline
\end{tabular}

$\mathrm{BE}$, Barrett's esophagus; PPI, proton pump inhibitor. 


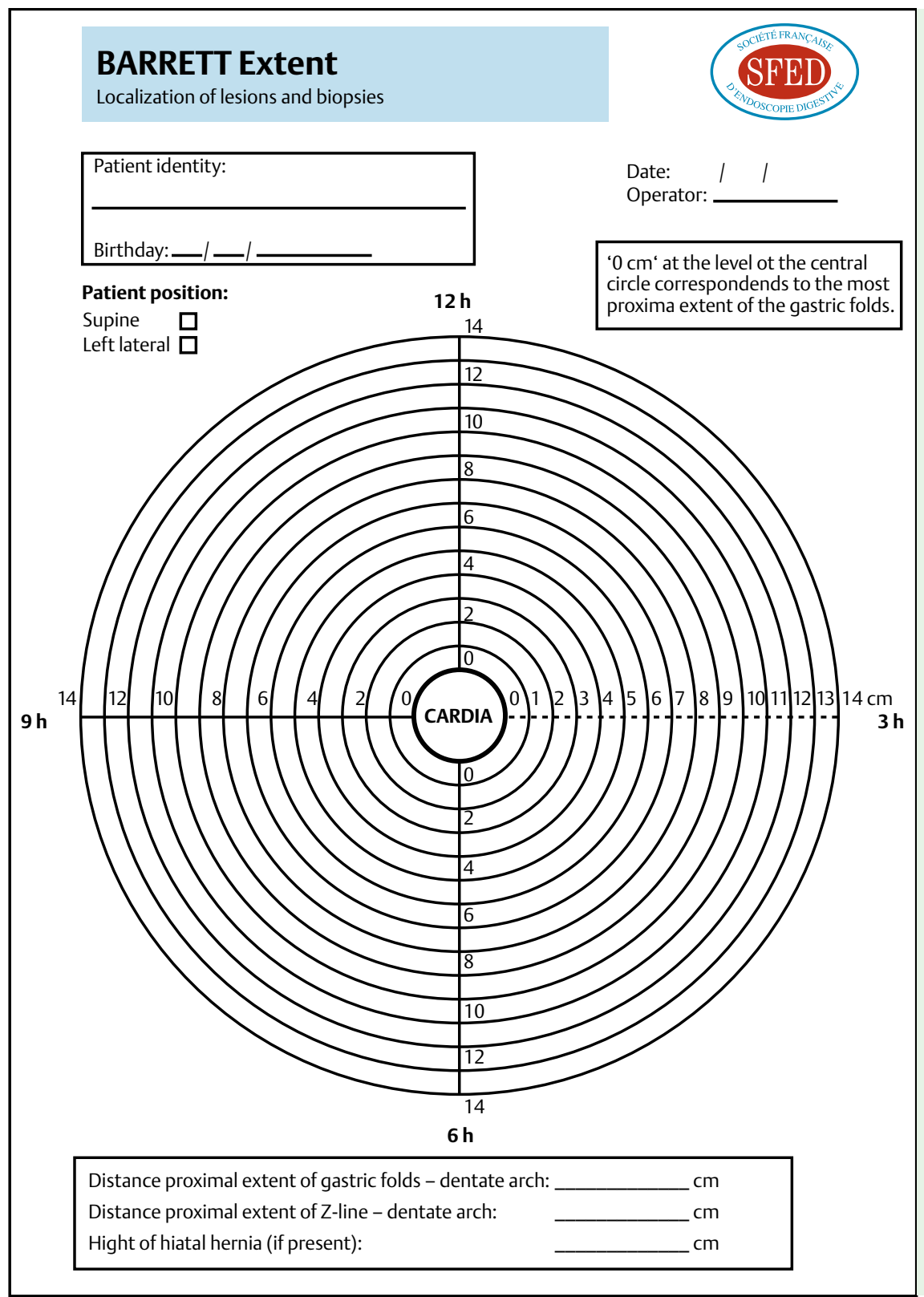

Fig. 1 SFED planimeter for the recording of site and extent of Barrett's esophagus at endoscopy.

in the case of long-segment Barrett's esophagus, a second-look endoscopy under general anesthesia must be scheduled in order to carry out the biopsy protocol under the proper conditions.

Dyes that stain intestinal metaplasia, such as methylene blue, are not required for the diagnosis of short- and long-segment Barrett's esophagus.

The endoscopy report must contain:

- Information about the location of the anatomical landmarks in relation to the dentate arch:

- Diaphragmatic hiatus.

- GEJ (most proximal extent of the gastric

folds or distal end of palisade vessels).

- Most proximal extent of the squamocolumnar epithelial line or $\mathrm{Z}$ line.

- Information about the length and width of any identified tongue and the length of the circular Barrett's esophagus. The Prague classification (CM) is recommended for characterization of Barrett's esophagus.

- Information about the height of any associated hiatal hernia.

\section{Biopsy protocol (using standard biopsy forceps)}

$\nabla$

- In cases of circular long-segment Barrett's esophagus:

- Any abnormality in the surface or the color of the mucosa must be biopsied, listed and put in a separate vial.

- Four biopsies (one on each side quadrant) should be obtained every $2 \mathrm{~cm}$ starting from the GEJ. Biopsies must be placed in separate vials (one vial per level) containing a $2 \%$ formalin solution.

- In cases of short-segment Barrett's esophagus or tongues: Two to four biopsies must be obtained every $1 \mathrm{~cm}$ starting from the GEJ. If any indentation of the Z-line is identified, it must be biopsied if its length is greater than $5 \mathrm{~mm}$.

- The SFED recommends indicating the site of each biopsy on a drawing (SFED planimeter, $\bigcirc$ Fig. 1), which is kept in the patient records. A copy must be sent to the pathologist with the endoscopy report. 
In cases of low-grade or high-grade dysplasia, a second histological examination must be performed by a different and independent pathologist.

- Chromoscopy with acetic acid, with or without new imaging methods (magnification, narrow band imaging or Fuji Intelligent Chromo Endoscopy - Fujinon Co., Omiya, Japan), may help to direct biopsies of high-grade dysplastic or carcinomatous areas, but cannot replace systematic random biopsies, as described above.

- Systematic biopsies of the GEJ for the detection of ultra-short Barrett's esophagus or cardial intestinal metaplasia are not recommended so far.

\section{Competing interests: None}

\section{References}

1 Boyce HW. Endoscopic definitions of oesogastric junction regional anatomy. Gastrointest Endosc 2000; 51: 586- 592

2 Boyer J. Aspects cliniques et endoscopiques de l'oesophage de Barrett. Gastroentol Clin Biol 1994; 18: D5 - 11

3 Chalasani N, WO JM, Hunter JC et al. Significance of intestinal metaplasia in different areas of oesophagus including oesogastric junction. Dig Dis Sci 1997; 42: 603-607

4 Dulai GS, Shekelle PG, Jensen DM et al. Dyplasia and risk of further neoplastic progression in a regional veterans administrations Barrett's cohort. Am J Gastroenterol 2005; 100: 775 - 783

5 Levine DS, Reid BJ. Endoscopic biopsy technique for acquiring larger mucosal samples. Gastrointest Endosc 1991; 37: 332 - 337

6 Levine DS. Haggitt RC, Blount PL. An endoscopic protocol can differentiate high-grade dysplasia from early adenocarcinoma in Barrett's oesophagus. Gastroenterology 1993; 105: 40-50
7 McClave SA, Boyce HW, Gottfried MR et al. Early diagnosis of columnarlined oesophagus: a new endoscopic criterion. Gastrointest Endosc 1987; 33: $413-416$

8 Provenzale D, Shmitt C, Wong JB. Barrett's esophagus: a new look at surveillance based on emerging estimates of cancer risk. Am J Gastroenterol 1999; 94: 2043 - 2053

9 Reaud S, Croue A, Boyer J. Diagnostic accuracy of magnifiying chromoendoscopy with detection of intestinal metaplasia and dysplasia using acetic acid in Barrett's esophagus. Gastroenterol Clin Biol. 2006; 30: 217-223

10 Rudolph RE, Vaughan TL, Storer BE et al. Effect of segment length on risk of neoplastic progression in patients with Barrett's oesophagus. Ann Intern Med 2000; 132: 612-620

11 Sampliner RE. Updated guidelines for the diagnosis, surveillance, and therapy of Barrett's oesophagus. Am J Gastroenterol. 2002; 97: 1888 1895

12 Schnell TG, Sontang SJ, Chejfec G et al. Long term non-surgical management of Barrett's esophagus with high-grade dysplasia. Gastroenterology 2001; 120: 1607-1619

13 Sharma P, Morales TG, Sampliner RE et al. Short segment Barrett's oesophagus: the need for standardization of the definition and diagnostic criteria. Am J Gastroenterol 1998; 93: 1033 - 1036

14 Skacel M, Petras RE, Gramlich TL et al. The diagnosis of low-grade dysplasia in Barrett's oesophagus and its implications for disease progression. Am J gastroenterol 2000; 95: 3383 - 3387

15 Thomas T, Richards CJ, De Caestecker JS et al. High-grade dysplasia in Barrett's oesophagus: natural history and review of clinical practice. Aliment Pharmacol Ther 2005; 21: 747-755

16 Weston AP, Krmpotich PT, Cherian $R$ et al. Prospective long term endoscopic and histologic follow-up of short segment Barrett's oesophagus: comparison with traditional long segment Barrett's oesophagus. Am J Gastroenterol. 1997; 92: 407-413

17 Weston AP, Sharma P, Mathur S et al. Risk stratification of Barrett's esophagus: Updated prospective multivariate analysis. Am J Gastroenterol 2004; 99: 1657-1666 